\title{
Painting a Rational Picture During Highly Emotional End-of-Life Discussions: a Qualitative Study of Internal Medicine Trainees and Faculty
}

\author{
Doaa El-Rouby, $\mathrm{MD}^{7}$, Nancy McNaughton, $\mathrm{PhD}^{7}$, and Dominique Piquette, MD MSc \\ MEd PhD ${ }^{1,2}$
}

${ }^{1}$ Faculty of Medicine, University of Toronto, Toronto, Canada; ${ }^{2}$ Department of Critical Care Medicine, Sunnybrook Health Sciences Centre, Toronto, ON, Canada.

BACKGROUND: High-quality communication about endof-life care results in greater patient and family satisfaction. End-of-life discussions should occur early during the patient's disease trajectory and yet is often addressed only when patients become severely ill. As a result, end-oflife discussions are commonly initiated during unplanned hospital admissions, which create additional challenges for physicians, patients, and families.

OBJECTIVE: To better understand how internal medicine attending physicians and trainees experience end-of-life discussions with patients and families during acute hospitalizations.

DESIGN: We conducted an interview-based qualitative study using an interpretivist approach. We selected participants based on purposeful maximal variation and theoretical sampling strategies. We conducted an individual, in-depth, semi-structured interview with each participant.

PARTICIPANTS: We recruited 15 internal medicine physicians with variable levels of clinical training and experience who worked in one of five university-affiliated academic hospitals.

APPROACH: Interview transcripts were analyzed inductively and reflectively. Data were grouped by themes and categories. Data collection and analysis occurred concurrently, led to iterative adjustments of the interview guide, and continued until theoretical sufficiency was reached.

KEY RESULTS: Physicians depicted end-of-life discussions as a process directed at painting a realistic picture of a clinical situation. By focusing their efforts on reaching a shared understanding of a clinical situation with patients/families, physicians self-delineated the boundaries of their professional responsibilities regarding endof-life care (i.e., help with understanding, not with accepting or making the "right" decisions). Information sharing took precedence over emotional support in most physicians' accounts of end-of-life discussions. However, the emotional impact of end-of-life discussions on families and physicians was readily recognized by participants.

Electronic supplementary material The online version of this article (https://doi.org/10.1007/s11606-019-05615-1) contains supplementary material, which is available to authorized users.

Received April 30, 2019

Revised August 23, 2019

Accepted December 12, 2019

Published online January 2, 2020
CONCLUSION: End-of-life discussions are complex, dynamic social interactions that involve multiple, complementary competencies. Focusing mostly on sharing clinical information during end-of-life discussions may distract physicians from providing emotional support to families and prevent improvements of end-of-life care delivered in acute care settings.

KEY WORDS: end-of-life care; communication; internal medicine.

J Gen Intern Med 35(4):1167-74

DOI: $10.1007 / \mathrm{s} 11606-019-05615-1$

(C) Society of General Internal Medicine 2020

\section{BACKGROUND}

Healthcare providers have the professional responsibility to provide high-quality care to patients nearing the end of their life. (1) Communicating with patients about their wishes, values, and beliefs regarding end-of-life care is of paramount importance for making decisions that are concordant with patient's preferences. (2, 3) High-quality communication about end-of-life care results in greater patient and family satisfaction, lower resources utilization and aggressiveness of care at end-of-life, and fewer conflicts between patients, families, and healthcare providers. (3) End-of-life discussions should ideally occur early in the course of a patient's disease trajectory and be initiated by a healthcare professional who knows the patient well. (4) Yet, physicians, patients, and families often fail to address end-of-life care before patients have become severely ill. (5-9) As a result, end-of-life discussions are commonly initiated during unplanned hospital admissions for life-threatening illnesses, when patients are no more competent to engage in complex decision-making, and by physicians who have no pre-established relationship with the patients. Unplanned end-of-life discussions during acute hospitalizations present specific challenges. $(10,11)$

\section{Barriers to Discussing End-of-Life Care During Acute Hospitalization}

Healthcare professionals report numerous barriers to discussing end-of-life care with seriously ill, hospitalized patients and their 
families. $(12,13)$ Healthcare providers identify patients' and relatives' difficulty in accepting a poor prognosis, limited understanding of the limitations and complications of lifesustaining treatments, reluctance to make high-stakes decisions, and disagreement among patients and family members as major patient-related barriers to effective communication around endof-life. (12) Healthcare providers appear to perceive physicianrelated barriers to optimal end-of-life discussions as less problematic than patient-related barriers. (12) However, many communication barriers related to physicians (e.g., discomfort with emotional conversations, deficient communication skills, uncertainty in predicting outcomes, attitudes towards end-of-life care) or to the healthcare system (e.g., time pressures, confusion about roles) have been identified as causes for delays and apprehension of end-of-life discussions. $(13,14)$ Moreover, physician barriers may be mitigated with adequate training.

\section{Training for Better End-of-Life Care During Acute Hospitalizations}

Better educational practices for physicians-in-training may improve end-of-life communication. $(1,15)$ However, the rapidly expanding literature on end-of-life communication training has provided, thus far, limited insights into effective educational strategies. Systematic reviews $(11,16)$ reveal heterogeneity of interventions; a paucity of studies using highquality design; outcome measures mostly focused on physicians' comfort, level of confidence, and knowledge rather than behavioral and patient-centered outcomes; and a need for additional research. Despite the multiplicity of educational initiatives, important gaps persist in the quality of end-of-life care provided to hospitalized, dying patients.

In this study, we chose to take a step back to better understand how physicians who routinely care for acutely ill, hospitalized patients experience end-of-life discussions with their patients and relatives. Gaining an in-depth understanding of physicians' perspectives on specific end-of-life discussions may reveal new insights into effective communication between physicians and acutely ill patients. Our main study objective was therefore to better understand how internal medicine attending physicians and residents experience endof-life discussions with patients and their relatives during acute hospitalizations. This knowledge will inform future interventions aimed at improving communication between physicians and severely ill patients in acute care settings.

\section{METHODS}

\section{Overview}

To address our research objective, we conducted an interviewbased qualitative study using an interpretivist approach. An interpretivist approach is concerned with understanding the meaning of a social phenomenon from the perspective of the participants. (17) Interpretivism recognizes the socially constructed nature of meaning making and focuses on human experience in specific social and cultural contexts. (17) Different perspectives of the same phenomenon are therefore viewed as equally valuable and highly influenced by the sociocultural and historical context. This study focused on general internal physicians' subjective experience of end-oflife discussions with patients (or patient relatives) admitted in tertiary academic hospitals with acute medical conditions.

\section{Research Team}

The inter-professional research team comprised of an internal medicine postgraduate trainee (D.E. PGY2 at the time of interviews), a critical care attending physician with primary specialty training in internal medicine and with expertise in medical education research (D.P.), and a non-clinician education scientist with a research interest on the role of emotions in health professional practice and education (N.M.). Every member of the research team had personal experience with end-of-life discussions, as a clinician (D.E. and D.P.) or as a standardized (simulated) patient/family member (N.M.) in different clinical contexts (ward, emergency room, intensive care unit, simulation).

\section{Participants and Setting}

For this study, we recruited 15 internal medicine physicians affiliated with the University of Toronto and working in 5 academic hospitals. Participants included 9 physicians-intraining (7 residents and 2 clinical fellows) and 6 certified practitioners with a wide range of clinical experience (from first year of postgraduate training to more than 20 years of practice). We chose to interview internal medicine practitioners because end-of-life discussions are routine practices during the hospital stay of patients admitted to this service for a new acute illness or for an acute deterioration of a chronic disease. Depending on the severity of the disease, these discussions typically take place either in the emergency department upon admission, or later during the patient hospital stay on a medical ward. Physicians therefore lack or have a limited relationship with the patients prior to these conversations.

\section{Sampling}

We used purposeful maximal variation sampling and theoretical sampling as our sampling strategies. $(18,19)$ Purposeful maximum variation sampling aims to capture a wide range of perspectives and insights regarding the phenomenon of interest. (18) Initial sampling targeted representation from physicians with various levels of clinical experience (junior residents (PGY1-2), senior residents (PGY3+) or fellows, early and mid-career practicing physicians), different institutions, and different types of end-of-life discussions (with patient vs. with relatives, elective vs. urgent). Further sampling was based on our preliminary findings to pursue promising lines of inquiry (theoretical sampling). (19) This sampling strategy 
provided richness and variation to the data set and created opportunities for in-depth analyses. Our final sample size was determined by theoretical sufficiency or "meaning saturation" (enough data available to support theoretical concepts and their relationships). (20)

\section{Data Collection}

After obtaining written consent, we conducted an individual, in-depth, semi-structured interview with each participant. The interviews were scheduled at a time and location convenient for the participants. The initial interview guide was designed to elicit the following:

1. A recollection of a recent or memorable end-of-life discussion held by the participant,

2. Circumstances perceived to have affected the physician's level of comfort and discomfort during past end-of-life discussions,

3. Characteristics of self-reported successful vs. unsuccessful end-of-life discussions,

4. Personal end-of-life views, values, and experiences.

The interview guide evolved iteratively based on preliminary analyses conducted concurrently with the data collection. For example, we added direct questions about personal emotions experienced during routine and challenging end-of-life discussions because of the lack of spontaneous comments made on this topic by participants. We also intentionally sought to gather additional information about discussions held directly with patients as opposed to meetings involving relatives only. Interviews lasted between 40 and 95 min and were conducted by $\mathrm{DE}$ or by a research assistant with expertise in qualitative interviewing.

\section{Data Analysis}

The interviews were transcribed verbatim and the anonymized interview transcripts were analyzed inductively and reflectively. (19) Two researchers (DE, DP) independently reviewed the transcripts of the initial 6 interviews using line-by-line coding. Data were grouped by themes and categories through the process of constant comparisons: within an interview between end-of-life discussions described; between interviews of participants belonging to different groups (e.g., residents, fellows, attending physicians) and institutions; and between different types of end-of-life discussion. (19) The two researchers (DE and DP) met to discuss their initial coding and established by consensus a preliminary coding schema, informing further data collection (theoretical sampling). (19) Data collection and analysis occurred concurrently, with iterative adjustments to the interview guide and preliminary coding schema until theoretical sufficiency was reached. (19) Regularly scheduled interprofessional research team meetings (DE, DP, NM) contributed, through researcher triangulation, to the development and refinement of our data interpretations throughout the research process. All analytical work was documented as analytical memos and kept as an audit trail. (19) The analysis was mindful of potential power dynamics between the research team and the study participants, as well as of the researchers' own subject positions. The final coding schema was then applied to all the transcripts. We used QRS NVivo10 for the storage and management of the data.

\section{Research Rigor}

To ensure the rigor of the research process, we used the following strategies: (1) purposeful and theoretical sampling; (2) in-depth interviews with rich descriptions of the circumstances/contexts in which end-of-life discussions occurred; (3) researcher triangulation (using multiple researchers from different backgrounds to review findings); and (4) reflexivity throughout the research process to ensure the integration of multiple perspectives into the interpretation of the participants' experiences. For example, researchers actively identified and openly discussed personal experiences of and perspectives on end-of-life discussions to keep their data interpretations in check.

\section{RESULTS}

From the participant perspective, end-of-life discussions were primarily focused on sharing clinical information about patient's current and future medical condition as realistically as possible. In doing so, physicians hoped that patients and their family developed clinical representations analogous to their own understanding. Many participants interpreted such shared cognitive understanding as a preliminary condition to rational decision-making and as the ultimate goal of a successful discussion. When achieved, shared understanding minimized physicians' distress despite disagreement about decision-making, especially among more experienced physicians. Based on the interviews, emotions were largely seen by physicians as interfering with the primary goal of end-of-life discussions (sharing and understanding information) and were generally addressed in order to achieve common understanding. Physician's emotions during end-of-life discussions were less commonly discussed explicitly by the participants.

[In the following sections, R\#, F\#, and AP\# refers respectively to resident, fellow, and attending physician participant number.]

\section{Painting a Realistic Picture}

Painting a realistic picture - or sharing detailed clinical information about a patient's current and future medical condition - was perceived as the core component of end-oflife discussions for the study participants. Physicians described their attempts at painting a vivid portrait of the current clinical status, treatment options, and expected outcomes for the patients and families involved in end-of-life discussions: 
And I think one of the things we struggle with in code status discussions is really painting a picture of what that might look like. (R4)

And I found that where I used to struggle with giving patients and families the sense like, a tangible sense of the potential outcomes. (R6)

The participants revealed different conditions that affected how graphic, dramatic, and detailed they could be about depicting the situation to the patient and their relatives. Strong opinions about the best decisional path for a given patient prompted physicians to paint a picture that included many concrete, visual details:

And I gave him a fairly bleak picture, just given how sick she was, how old she was, her medical comorbidities and he [the son] was very dismissive of some of the potential and serious negative possibilities of an ICU admission. (R5)

Clinical experience, a good understanding of a patient's clinical trajectory, or a typical clinical situation with little clinical uncertainty increased participants' confidence in their ability and perceived need to paint a clear and realistic picture of the situation:

I think in cases where it is difficult to prognosticate it is always very difficult to make recommendations to the family. (F1)

I think we have lots of experience in doing this [making recommendations] and participating in the care of these patients. We understand what the expected course is. So that is a part of actually sharing medical information. I can say: in the past, when I've seen people with your condition, this is the expected course. (AP5)

For both junior and senior physicians, the desire to paint as realistic a picture as possible was rooted into a deep sense of responsibility towards the patient. It was regarded as a major professional and moral duty:

I said: Look, you have a condition that is going to get worse and you need to have those conversations with your family members or with your family doctor about what to do when it gets to a moment when there is nothing reversible. So I think that approaching that subject is a responsibility for sure. (R1)

If it is clear that the prognosis is not good, I feel like it is my job as a doctor to tell this to the family in an honest and sensitive way as best as I can. (F1)

Clinically experienced participants reported having privileged knowledge of what dying from different medical conditions and in different settings (e.g., in the intensive care unit vs. in the palliative care unit) looks like. They reported having seen similar patients before and having experienced first-hand other patients' suffering. This knowledge appeared to color the picture being painted during subsequent end-oflife discussions.

I felt I knew how it was going to end... we have put her through too much of suffering that she did not need to go through for the same outcome. (F1)

Although I do not think I know everything now, I still can say with certainty that if you are in the ICU for a long time, you are going to be worse than before coming to the ICU and you are going to have a long recovery. I think that when you are a junior resident it is hard to say those kinds of things with confidence and shouldn't, if you do not know what the outcome would be. (AP1)

Our study participants perceived that sharing clinical information, as realistically as possible depending on clinical circumstances, was of paramount importance during end-of-life discussions. The motivation to paint a realistic picture of the clinical situation was based on professional and ethical values, but also influenced by physicians' previous clinical experiences with end-of-life care.

\section{Finding Common Ground}

While painting a picture of a patient's clinical condition, physicians monitored and interpreted patient and family's reactions indicating progression towards decision-making regarding end-of-life care. Participants described this progression as a three-step process: cognitive understanding, acceptance, and decision-making. Many participants spoke about patient and family's understanding of the clinical situation (getting the picture) as the key milestone to achieve for a successful end-of-life discussion.

A successful end-of-life discussion for me is when the patient and/ or family member has a good understanding of what their disease is. (R1)

You have a very meaningful conversation, they get to understand what is going on, you understand how they feel and we are all on the same page at least in terms of understanding. (AP3)

Physicians carefully sought for clues that reflected patients and relatives' understanding, such as asking (or not asking) relevant questions and displaying expected emotions.

[A successful discussion], for me, is to feel like they are exactly understanding what end-of-life involves and what resuscitation involves, and for them to ask the appropriate questions. [...] They do not really say they do not understand. I think this is my interpretation that they do not quite understand everything based on what they say and the lack of questions. (R2)

I think the daughter was so enmeshed with the situation that she was not objectively seeing, and I do not think she ever appreciated how sick her mom was. [...] When people get it, they get a bit tearful or they will say: "we did not realize it was that serious." But she took it: "ok, her blood pressure is high, we will try to fix it." She did not seem to get what I was getting to. (AP4)

Perceived failure to help patients or families understand the clinical information caused distress among physicians:

I think the only time I feel I have failed is when I feel the family did not understand the facts. (AP3)

If they do not understand the medical piece, then we are failing as communicator. (AP5) 
Some physicians acknowledged the importance for them to understand patient and family's views and rationale for decision-making. Understanding the reasoning behind a patient or family's end-of-life decision was another way for physicians to establish common ground:

I think it is very important to me to seek enough information to understand the patient or the family's perspective on whatever the point of conflict is. (F2)

And so, usually, I ask them why - like, I usually get them to talk more than me at first so that I know - I try and know what they're thinking and they're feeling and why. And what do you understand about what's going on? (R6)

Although physicians expressed a perceived responsibility to facilitate patients and families' understanding of a clinical situation, they felt that the patients and families' acceptance of the situation and ability to make decisions aligned (in their opinion) with patient's best interests was not under their control. Establishing a common ground by gaining a mutual understanding of each other's rationale for medical recommendations and decisions was, in our participants' view, the objective of end-of-life discussions.

If people say: "full code" at the end of that... like really understand all of those things... you know, fine! (R1)

If you ask me what makes for a bad discussion, this is sort of what it is, you go in and you can't find a common ground, and you cannot figure out what is going on. (R3)

However, based on certain physicians' accounts, the distinction between a patient's or family's lack of understanding and lack of acceptance of a clinical situation could be hazy. Some physicians questioned the patient and family's ability to understand when overwhelmed by grief.

I don't know how you would understand something if you cannot accept it anyways. My read of the situation was that it was all grief. (R3)

It is part of their grief response, and they are not in a place where they are willing to accept the course of illness. And I know that generally what happens is that after repeated hospital admissions, they will most of the time come to a place where they understand. (AP5)

Many participants also reported negative emotions such as frustration or anxiety when being obliged to provide treatments perceived as futile and causing suffering.

I think that it can be frustrating when you end up with a decision that you think is not in the best interest of the patient for sure. (R4)

By focusing their efforts on reaching a shared understanding of the clinical situation and of a rationale for decisionmaking, our participants self-delineated the boundaries of their professional responsibilities regarding end-of-life care (i.e., help patients and relatives to understand, not to accept or make the "right" decisions). When a patient or family's end-of-life decision did not align with a physician's views of a clinical situation, these boundaries mitigated physician's negative reactions to the decision. However, it did not always shield physicians from negative emotions associated with the delivery of life-sustaining therapy to dying patients.

\section{Managing Overwhelming Emotions}

Patients' and families' emotions were most commonly depicted by the participants as something that needed to be addressed in order to achieve a shared understanding of the medical situation and a "rational" decision.

She [the daughter of a sick patient] is like freaking out... it is all anxiety, and she is not even processing what the discussion is about. (R3)

But as I started the conversation, I realized that they [the family members] were very anxious and very tearful and that made them less able to appreciate what I was saying. I think that is why it was challenging to communicate when they were really stressed out: Oh... he is going to die... oh... you have to save him! (R2)

If they [the family members] are hostile but have a little bit of insight into the situation, you can turn the conversation around and say that they may be feeling angry because their family member is sick or because they see him deteriorating; and you can sort of turn the focus of the conversation back to their family member and what is best for this person. (F1)

These views did not prevent participants to express empathy towards patients and families involved in end-of-life decisions.

$[\ldots\}$ my focus is always on trying to explain things as clearly as I can and to provide as much support as I can for that family because it's obviously a really difficult conversation. (R5)

However, only two participants mentioned explicitly that emotional support was an integral aspect of end-of-life discussions.

They are human beings and they are going through a very tough time. [...] Dealing with situations of live and death are very emotionally challenging. But I always say to the families, I am not here for the patient only, we are here for you as well, tell us how we can help you. (AP2)

So, you know, I mostly sat with him for support. And he was very sad. And his son came in, and that's when I left. I just didn't want him to sit there by himself. And mostly, we talked about the stuff that they [he and his wife, the patient] did together and his kids and his grandkids. (F2)

Participants also reported making conscious efforts to minimize patients' and family's negative reactions and, at times, felt responsible for these emotions:

My gut reaction is always to give a silver lining because I don't want people to feel bad. (R7)

People do not want a physician who is defensive, people want empathy, and they want someone at their side [...]. And I have to reflect back to them what they are saying in different words so that they can understand that I'm hearing their concerns without sounding judgemental or defensive. (AP1) 
I think anger is probably the most challenging [family's emotion to deal with]. That makes me feel that probably there is something [in terms of communication] that I could have done better leading to the patient's clinical deterioration. (R2)

Participants had difficulty commenting spontaneously and explicitly about the nature and the role of their own emotions during end-of-life discussions, though their emotional responses to past end-of-life discussions pervaded the content of each interview. With direct questioning and additional probing, physicians' emotions emerged as an important aspect of end-of-life discussions.

Physicians admitted that they intentionally avoid thinking about their own feelings at times and purposefully suppressed emerging emotions during their conversations with patients and families:

You don't want to get so wrapped up in your own feelings that you lose the ability or lose focus of everything else that's going on. (R5)

That is something that I've learned to manage: if you're becoming frustrated, it is not productive. So you need to learn to recognize that you're feeling frustrated and that it's not good for healthy communication. (AP5)

In spite of the paucity of explicit comments about participants' own emotions during end-of-life discussions, participants commonly qualified these discussions as uncomfortable and emotionally exhausting:

I think one of the things with having these repeated family meetings... I think they are emotionally exhausting, whether or not they are tensions between those participating. (AP1)

And I have to catch myself sometimes thinking " $\mathrm{Oh}$ if only they had made the decision today, I wouldn't have to do one more family meeting over the next couple of weeks because those are hard to do. It's a lot of work and it's tiring and it's emotionally exhausting to go through a family meeting." (F2)

Participants also commented on coping strategies they had developed in response to the perceived burden associated with conducting certain end-of-life discussions:

I have sort of started to think that this is my job, and I am here to do the best I can and to support these people the best I can, but I can't be sad for all of them. (AP1)

I usually just have to talk to somebody about it. I talk to my husband, sometimes I call my parents. I talk to some of my close friends. I'll write about it because I kind of express myself a bit better in writing than I do otherwise. Sometimes I just have to distract myself, like watch a comedy [...]. (R5)

The physicians we interviewed spoke more easily about a patient and relative's emotional responses to end-of-life discussions than of their own emotions. Physicians generally perceived emotions as an aspect of end-of-life discussions that needed to be addressed in order to achieve a shared understanding of the situation with the patients/families during endof-life discussions. However, physicians also expressed empathy for patients and families as they recognized the challenges associated with end-of-life decision-making. Based on participant's accounts, the management of physicians' own emotions during end-of-life discussions was not without personal cost and led to the use of coping strategies.

\section{DISCUSSION}

In many countries and despite recent advances in palliative care and advanced care planning, patients continue to die predominantly in acute care hospitals. (21) For many of these patients, end-of-life discussions will be delayed until the end of the disease trajectory. (3) This interview-based qualitative study aimed at gaining an in-depth understanding of internal medicine physicians' lived experience of end-of-life discussions with patients or families during acute hospitalizations.

\section{An Emotionally Laden Clinical Picture}

Our participants depicted end-of-life discussions as a process largely focused on painting a realistic picture of a clinical situation for the patients and their relatives. Physicians presented the clinical information shared with patients and families as an "objective" reality that must be accepted by patients and families and described their recommendations as anchored on professional knowledge developed through clinical experience. However, participants' accounts revealed that the clinical picture painted by physicians was not only shaped by their medical expertise but also by their past experiences as direct witnesses of previous - at times strongly emotional—patient's death. As such, painting a picture, although presented as an emotionally neutral process by our participants, could be interpreted as an emotionally laden one. Recognizing and understanding how emotions experienced during end-of-life care affect subsequent end-of-life discussions may increase physicians' awareness of their emotional responses during end-of-life discussions and improve the quality of their interactions with patients and families.

\section{Gaps Between Theoretical Frameworks and Clinical Practices Related to End-of-Life Discussions}

Physicians' focus on medical facts during end-of-life discussions has been previously reported, as well as its negative consequences for dying patients. $(1,22-24)$ To address patients and families' predictable negative emotions during end-of-life discussions, care models like patient-centered care (25), person-centered care (26), and shared decision-making (27) have been increasingly promoted to improve end-of-life care. These models recognize emotional support to patients and relatives as a fundamental goal of end-of-life discussions. Yet, purposefully and successfully addressing emotions emerging during end-of-life discussions was infrequently described as a fundamental goal to achieve, source of satisfaction, or criteria of success by our participants (with two exceptions). We do not imply that participants were unable or unwilling to display empathy or to help patients and 
families in distress, but that in many of their accounts of endof-life discussions, emotions appeared subordinate to cognition. This could be problematic for two reasons: first, patients and families are at times mainly in need of emotional support rather than medical information and failing to recognize this need will result in an inability to address them; second, physicians who value equally the importance of emotional support and information sharing may experience more rewards and less dissatisfaction during end-of-life discussions, especially when a shared understanding cannot be achieved.

Interestingly, both junior and senior study participants reported a focus on cognition (reaching a shared understanding of a clinical situation) over emotions during end-of-life discussions. Yet, junior physicians from the participating institution had received formal communication training not offered during their senior counterparts' training. This suggests that communication training may improve physicians' comfort and abilities in sharing understandable medical information with patients and families but neglect to address strategies used by physicians to deal with intense emotional reactions. The skills required to recognize and respond appropriately to emotions experienced by patients and families are complex. Physicians' emotional competence (28) needs to be developed and supported in practice. However, the type of educational strategies typically used in many institutions to address endof-life communication (e.g., half-day communication workshops or lecture series) may fail to address emotional competence. $(11,16)$

Beyond communication training, other factors may contribute to a lack of prioritization of emotional support during endof-life discussions. For example, our participants expressed a strong sense of responsibility towards their patients primarily and less so towards the patients' relatives. When end-of-life discussions were held with families or surrogates, unique challenges emerged. Physicians struggled supporting emotionally families who made decisions that physicians perceived as unhelpful or harmful to the patients. Physicians may not feel professionally compelled to feel or express empathy for families who adopt a plan of care misaligned, in their views, with patient's best interests.

Limitations. This study presents limitations. First, participants may have felt uncomfortable discussing emotions with the interviewers. In addition, interviews provided retrospective, distant views on events experienced by participants. Direct observations of end-of-life discussions followed by immediate interviews may have facilitated participants' identification and reflections on their own emotional responses. This study focused on end-of-life discussions occurring in inpatients and may not reflect end-of-life discussions conducted in other settings. The participants mostly described end-of-life discussions for patients suffering from acute, life-threatening conditions, and findings may not be transferrable to elective endof-life discussions. Finally, our data did not allow us to fully explore potential differences between views of junior and senior physicians.
Practical Implications. Based on our findings, we argue that much more need to be done to ensure that physicians develop the full range of competencies required to improve end-of-life discussions and end-of-life care. The importance of emotions in communication and decision-making is increasingly considered in published recommendations and guidelines on endof-life communication. $(1,27,29,30)$ Many have recognized the limitations of existing patient-physician interaction models such as shared decision-making. To be effective, shared decision-making relies on physician's ability to recognize, through communication, how decision-making is biased by prior beliefs, experiences, and emotions of physicians, patients, and families and how to intervene accordingly. (27) The best ways to learn these skills in the medical context are largely unknown. However, a range of communication training initiatives are rapidly developing in different jurisdictions, accompanied by emerging evidence supporting benefits for patients and physicians. $(31,32)$ We believe that such initiatives should be further studied, as evidence-based communication training specifically focused on the awareness, acceptance, and understanding of physicians, patients, and relatives' positive and negative emotions would greatly contribute to the improvement of end-of-life care.

Corresponding Author: Dominique Piquette, MD MSc MEd PhD, Department of Critical Care Medicine Sunnybrook Health Sciences Centre, 2075 Bayview Ave, Room D108, Toronto, ON M4N 3M5, Canada (e-mail: dominique.piquette@sunnybrook.ca).

\section{Compliance with Ethical Standards:}

Conflict of Interest: Dominique Piquette has no conflict of interest to declare.

Doaa El-Rouby has no conflict of interest to declare.

Nancy McNaughton has no conflict of interest to declare.

\section{REFERENCES}

1. Committee on Approaching Death: Addressing Key End of Life Issues; Institute of Medicine. Dying in America: Improving Quality and Honoring Individual Preferences Near the End of Life. Washington (DC): National Academies Press; 20152015 Mar 19.

2. A controlled trial to improve care for seriously ill hospitalized patients. The study to understand prognoses and preferences for outcomes and risks of treatments (SUPPORT). The SUPPORT Principal Investigators. Jama. 1995;274(20):1591-8.

3. Sinuff T, Dodek P, You JJ, Barwich D, Tayler C, Downar J, et al. Improving End-of-Life Communication and Decision Making: The Development of a Conceptual Framework and Quality Indicators. J Pain Symptom Manage. 2015;49(6): 1070-80.

4. Pinkowish MD. End-of-life care: Communication and a stable patientphysician relationship lead to better decisions. CA Cancer $\mathrm{J}$ Clin. 2009;59(4):217-9.

5. Kale MS, Ornstein KA, Smith CB, Kelley AS. End-of-Life Discussions with Older Adults. J Am Geriatr Soc. 2016;64(10):1962-7.

6. Heyland DK, Dodek P, Mehta S, Cook D, Garland A, Stelfox HT, et al. Admission of the very elderly to the intensive care unit: family members' perspectives on clinical decision-making from a multicenter cohort study. Palliat Med. 2015;29(4):324-35.

7. Heyland DK, Ilan R, Jiang $\mathbf{X}$, You JJ, Dodek P. The prevalence of medical error related to end-of-life communication in Canadian hospitals: 
results of a multicentre observational study. BMJ Qual Saf. 2016;25(9):671-9.

8. Houben CH, Spruit MA, Schols JM, Wouters EF, Janssen DJ. PatientClinician Communication About End-of-Life Care in Patients With Advanced Chronic Organ Failure During One Year. J Pain Symptom Manage. 2015;49(6):1109-15.

9. Janssen DJ, Curtis JR, Au DH, Spruit MA, Downey L, Schols JM, et al. Patient-clinician communication about end-of-life care for Dutch and US patients with COPD. Eur Respir J. 2011;38(2):268-76.

10. Hewison A, Lord L, Bailey C. "It's been quite a challenge": Redesigning end-of-life care in acute hospitals. Palliative and Supportive Care. 2014;13(03):609-18.

11. Lord L, Clark-Carter D, Grove A. The effectiveness of communicationskills training interventions in end-of-life noncancer care in acute hospital-based services: A systematic review. Palliative and Supportive Care. 2015;14(04):433-44.

12. You JJ, Downar J, Fowler RA, Lamontagne F, Ma IW, Jayaraman D, et al. Barriers to goals of care discussions with seriously ill hospitalized patients and their families: a multicenter survey of clinicians. JAMA Intern Med. 2015;175(4):549-56.

13. Visser M, Deliens L, Houttekier D. Physician-related barriers to communication and patient- and family-centred decision-making towards the end of life in intensive care: a systematic review. Crit Care. 2014;18(6):604.

14. Nedjat-Haiem FR, Carrion IV, Gonzalez K, Ell K, Thompson B, Mishra SI. Exploring Health Care Providers' Views About Initiating End-of-Life Care Communication. Am J Hosp Palliat Care. 2017;34(4):308-17.

15. Roze des Ordons A, Ajjawi R, Macdonald J, Sarti A, Lockyer J, Hartwick M. Palliative and end of life care communication as emerging priorities in postgraduate medical education. Can Med Educ J. 2016;7(1):e4-e21.

16. Brighton LJ, Koffman J, Hawkins A, McDonald C, O'Brien S, Robinson V, et al. A Systematic Review of End-of-Life Care Communication Skills Training for Generalist Palliative Care Providers: Research Quality and Reporting Guidance. J Pain Symptom Manage. 2017;54(3):417-25.

17. Hammersley M. What is Qualitative Research? London and New York: Bloomsburry; 2013

18. Teddlie C, Yu F. Mixed Methods Sampling. Journal of Mixed Methods Research. 2016;1(1):77-100.

19. Charmaz K. Constructing grounded theory: A practical guide through qualitative analysis. London: SAGE Publications; 2006.

20. Hennink MM, Kaiser BN, Marconi VC. Code Saturation Versus Meaning Saturation. Qualitative Health Research. 2016;27(4):591-608.
21. Bekelman JE, Halpern SD, Blankart CR, Bynum JP, Cohen J, Fowler $\mathbf{R}$, et al. Comparison of Site of Death, Health Care Utilization, and Hospital Expenditures for Patients Dying With Cancer in 7 Developed Countries. Jama. 2016;315(3).

22. Weiner JS, Roth J. Avoiding iatrogenic harm to patient and family while discussing goals of care near the end of life. J Palliat Med. 2006;9(2):45163.

23. Fine E, Reid MC, Shengelia R, Adelman RD. Directly Observed PatientPhysician Discussions in Palliative and End-of-Life Care: A Systematic Review of the Literature. Journal of Palliative Medicine. 2010;13(5):595603.

24. Pollak KI, Arnold RM, Jeffreys AS, Alexander SC, Olsen MK, Abernethy AP, et al. Oncologist communication about emotion during visits with patients with advanced cancer. J Clin Oncol. 2007;25(36):5748-52.

25. Ngo-Metzger Q, August KJ, Srinivasan M, Liao S, Meyskens FL, Jr. End-of-Life care: guidelines for patient-centered communication. Am Fam Physician. 2008;77(2): 167-74.

26. Person-Centered Care: A Definition and Essential Elements. Journal of the American Geriatrics Society. 2016;64(1):15-8.

27. Azoulay E, Chaize M, Kentish-Barnes N. Involvement of ICU families in decisions: fine-tuning the partnership. Ann Intensive Care. 2014;4:37.

28. McNaughton N, LeBlanc VR. Perturbations: The central role of emotion competence in health professinal training. In: Lingard L, Hodges B, editors. The Question of Competence: Reconsidering Medical Education in the Twenty-First Century. New York: Cornell Press; 2012

29. Gilligan T, Bohlke $\mathbf{K}$, Baile WF. Patient-Clinician Communication: American Society of Clinical Oncology Consensus Guideline Summary. J Oncol Pract. 2018;14(1):42-6.

30. Bernacki R, Hutchings M, Vick J, Smith G, Paladino J, Lipsitz S, et al. Development of the Serious Illness Care Program: a randomised controlled trial of a palliative care communication intervention. BMJ Open. 2015;5(10):e009032.

31. Boissy A, Windover AK, Bokar D, Karafa M, Neuendorf K, Frankel RM, et al. Communication Skills Training for Physicians Improves Patient Satisfaction. J Gen Intern Med. 2016;31(7):755-61.

32. Back AL, Fromme EK, Meier DE. Training Clinicians with Communication Skills Needed to Match Medical Treatments to Patient Values. J Am Geriatr Soc. 2019;67(S2):S435-S41.

Publisher's Note Springer Nature remains neutral with regard to jurisdictional claims in published maps and institutional affiliations. 